\title{
Staging for Ampullary Carcinoma: Is Less Actually More?
}

\author{
Jordan M. Cloyd, MD \\ Department of Surgery, Division of Surgical Oncology, The Ohio State University Wexner Medical Center, Columbus, OH
}

Adenocarcinoma of the ampulla of Vater, or ampullary carcinoma (AC), is a relatively rare cancer, comprising $<0.5 \%$ of all gastrointestinal cancers and approximately $7 \%$ of all periampullary cancers. ${ }^{1,2}$ Similar to other periampullary malignancies, the surgical management of AC involves resection of the primary tumor and regional lymph nodes via pancreatoduodenectomy. In general, $\mathrm{AC}$ is associated with an improved long-term prognosis (median 41 months overall survival [OS]) following surgical resection compared with other periampullary cancers. ${ }^{3}$

The ampulla of Vater represents the common junction of the distal common bile duct and the main pancreatic duct of Wirsung as it enters into the second portion of the duodenum. It is surrounded by smooth muscle fibers known as the sphincter of Oddi, which regulates the flow of bile and pancreatic juice through the major duodenal papilla. The smooth muscle fibers are interspersed with glandular tissue which secretes directly into the ampulla. ${ }^{4}$ Cancers can arise from anywhere along the ampulla of Vater and are therefore at risk for direct extension into the sphincter of Oddi, duodenum, and/or pancreas. While beyond the scope of this editorial, the marked anatomic complexity, the variable $3 \mathrm{D}$ pattern of spread, and non-uniform histopathologic grossing practices makes the proper staging of $\mathrm{AC}$, especially with regard to the $\mathrm{T}$ category of the tumor, node, and metastasis (TNM) system, particularly challenging. ${ }^{5}$

Since 2010, AC has been staged according to the American Joint Committee on Cancer (AJCC) and Union for International Cancer Control (UICC) 7th edition, which categorizes the $\mathrm{T}$ stage according to four standard

(C) Society of Surgical Oncology 2019

First Received: 22 January 2019;

Published Online: 20 February 2019

J. M. Cloyd, MD

e-mail: jordan.cloyd@osumc.edu classifications (Table 1). The recently released 8th edition fostered several distinct changes to the $\mathrm{T}$ and $\mathrm{N}$ classification that, in general, added complexity to the staging system. ${ }^{6}$ First, subcategories were introduced for the $\mathrm{T}$ stage based on depth of invasion into the duodenum (T1b, invasion into the duodenal submucosa, versus $\mathrm{T} 2$, invasion into the duodenal muscularis propria) and pancreas (T3a, invasion into the pancreas $<0.5 \mathrm{~cm}$, versus T3b, invasion into the pancreas $>0.5 \mathrm{~cm}$ or duodenal subserosa). In addition, the $\mathrm{N}$ classification was expanded to $\mathrm{N} 1$ (one to three positive lymph nodes) and N2 (four or more positive lymph nodes).

The 8th edition of the AJCC staging is also notable for the introduction of levels of evidence for its staging updates. $^{7}$ Notably, the levels of evidence for the T-stage changes in the 8th edition were stated as level III (limited evidence due to the number, size or quality of individual studies, or inconsistent results across studies), while the $\mathrm{N}$-stage changes were described as level II (at least one large, well-designed, well-conducted study). ${ }^{7}$ The original study by Imamura et al. published in this issue of Annals of Surgical Oncology, ${ }^{8}$ evaluating the prognostic relevance of the new TNM staging system for AC, is therefore an appropriate and timely addition to the literature.

Imamura et al. analyzed 104 consecutive patients from a single institution who underwent curative intent surgical resection for AC. They found that the 8th edition AJCC T classification continued to demonstrate poor risk stratification, concluding that the new subcategories did not improve prognostic accuracy. Specifically, there were no differences in recurrence-free survival (RFS), OS, lymphatic invasion, venous invasion, or lymph node metastases between T1b (duodenal submucosa) and T2 (duodenal muscularis) tumors, while significant differences were observed in RFS and OS between T3a (pancreas $\leq 0.5 \mathrm{~cm}$ ) and T3b (pancreas $>0.5 \mathrm{~cm}$ ) tumors. In addition, the authors also found differences in RFS based on the updated $\mathrm{N}$ classification, and therefore proposed a new simplified 
TABLE 1 Comparison of the 7th and 8th editions of the AJCC/UICC classification and staging systems for ampullary carcinoma

\begin{tabular}{|c|c|c|c|}
\hline \multicolumn{2}{|c|}{ 7th edition } & \multicolumn{2}{|c|}{ 8th edition } \\
\hline \multicolumn{4}{|l|}{$\mathrm{T}$} \\
\hline \multirow[t]{2}{*}{$\mathrm{T} 1$} & Limited to ampulla or sphincter of Oddi & T1a & Limited to sphincter of Oddi \\
\hline & & $\mathrm{T} 1 \mathrm{~b}$ & Invasion into duodenal submucosa \\
\hline $\mathrm{T} 2$ & Invasion into duodenal wall & $\mathrm{T} 2$ & Invasion into duodenal muscularis propria \\
\hline \multirow[t]{2}{*}{ T3 } & Invasion into pancreas & $\mathrm{T} 3 \mathrm{a}$ & Invasion into pancreas $\leq 0.5 \mathrm{~cm}$ \\
\hline & & $\mathrm{T} 3 \mathrm{~b}$ & Invasion into pancreas $>0.5 \mathrm{~cm}$ or duodenal subserosa \\
\hline $\mathrm{T} 4$ & Invasion into peripancreatic soft tissue or other adjacent organs & $\mathrm{T} 4$ & Involvement of celiac or superior mesenteric artery \\
\hline \multicolumn{4}{|l|}{$\mathrm{N}$} \\
\hline N0 & No lymph node involvement & N0 & No lymph node involvement \\
\hline \multirow[t]{2}{*}{ N1 } & Lymph node involvement & N1 & Metastasis in 1-3 lymph nodes \\
\hline & & $\mathrm{N} 2$ & Metastasis in $\geq 4$ lymph nodes \\
\hline \multicolumn{4}{|c|}{ AJCC stage } \\
\hline IA & T1, N0, M0 & IA & T1a, N0, M0 \\
\hline IB & T2, N0, M0 & IB & T1b-2, N0, M0 \\
\hline IIA & T3, N0, M0 & IIA & T3a, N0, M0 \\
\hline IIB & T1-3, N1, M0 & IIB & T3b, N0, M0 \\
\hline \multirow[t]{3}{*}{ III } & $\mathrm{T} 4$, any $\mathrm{N}, \mathrm{M} 0$ & IIIA & T1a-T3, N1, M0 \\
\hline & & IIIB & Any $\mathrm{T}, \mathrm{N} 2, \mathrm{M} 0$ \\
\hline & & & $\mathrm{T} 4$, any $\mathrm{N}, \mathrm{M} 0$ \\
\hline IV & Any T Any N M1 & IV & Any $\mathrm{T}$, any $\mathrm{N}, \mathrm{M} 1$ \\
\hline
\end{tabular}

AJCC American Joint Committee on Cancer, UICC Union for International Cancer Control

reclassification of the $\mathrm{T}$ staging by omitting the subcategories: T1, limited to sphincter of Oddi; T2, invasion into the duodenal submucosa or muscularis propria; T3, invasion into the pancreas $\leq 0.5 \mathrm{~cm}$ or duodenal subserosa; $\mathrm{T} 4$, invasion into the pancreas $>0.5 \mathrm{~cm}$. The authors then demonstrated that both the revised $\mathrm{T}$ stage and their resultant overall staging classification demonstrated improved prognostic stratification.

The findings in the current study are not significantly different than those of Kim et al., ${ }^{9}$ who also found deficiencies in the AJCC 8th edition's T classification for AC. Interestingly, these authors proposed a revised $\mathrm{T}$ classification that also removed the $\mathrm{T}$ subclassifications, but was ultimately different than that of Imamura et al. These discrepancies call to attention not only the challenges of validating staging systems based on retrospective singleinstitution series but also the unique constraints that pertain specifically to AC. Due to its anatomic complexity and challenges with gross and microscopic examination, it is not uncommon for $\mathrm{AC}$ to be misdiagnosed as pancreatic ductal adenocarcinoma, distal cholangiocarcinoma, or duodenal adenocarcinoma. Stringent histopathologic review is necessary to differentiate these distinct cancers given their different prognoses and systemic therapy options. In addition, the role of neoadjuvant and adjuvant therapy remains controversial for $\mathrm{AC}$, but the lack of its use in the current study (i.e. $<10 \%$ of patients received any pre-or postoperative therapy) may have biased the survival outcomes. Finally, increasing evidence suggests that intestinal and pancreatobiliary are distinct subtypes of AC with markedly different prognoses. ${ }^{10}$ The absence of data on AC subtype in the studies used to either derive or validate the AJCC staging system could potentially bias the results.

The 8th edition AJCC staging manual continues in its effort to transition from a 'population-based' to a 'personalized' approach to cancer staging. ${ }^{7}$ However, to do so will require ongoing advancements in our understanding of the molecular features of AC. In recent years, the genomic landscape of $\mathrm{AC}$ has been elucidated, but how this translates to patient prognosis and/or personalized therapy remains uncertain. However, until this data becomes mature, continued refinement of the current classification systems, particularly the $\mathrm{T}$ classification, via meticulous assessment of traditional anatomical and histopathological factors, will be critical to providing proper staging guidelines. Studies utilizing larger patient series via international multi-institutional collaborations should help in that effort.

\section{REFERENCES}

1. Albores-Saavedra J, Schwartz AM, Batich K, et al. Cancers of the ampulla of vater: demographics, morphology, and survival based on 5,625 cases from the SEER program. J Surg Oncol. 2009; 100:598-605. 
2. Michalski CW, Liu B, Heckler M, et al. Underutilization of surgery in periampullary cancer treatment. J Gastrointest Surg. 2018. https://doi.org/10.1007/s11605-018-3897-4.

3. Kamarajah SK. Pancreaticoduodenectomy for periampullary tumours: a review article based on surveillance, end results and epidemiology (SEER) database. Clin Transl Oncol. 2018;20:1153-60.

4. Avisse C, Flament JB, Delattre JF. Ampulla of vater. Anatomic, embryologic, and surgical aspects. Surg Clin $N \mathrm{Am}$. 2000;80:201-12.

5. Adsay NV, Bagci P, Tajiri T, et al. Pathologic staging of pancreatic, ampullary, biliary, and gallbladder cancers: pitfalls and practical limitations of the current AJCC/UICC TNM staging system and opportunities for improvement. Semin Diagn Pathol. 2012;29:127-41.

6. Chun YS, Pawlik TM, Vauthey J-N. 8th edition of the AJCC cancer staging manual: pancreas and hepatobiliary cancers. Ann Surg Oncol. 2018;25:845-7.

7. Amin MB, Greene FL, Edge SB, et al. The eighth edition AJCC Cancer staging manual: continuing to build a bridge from a population-based to a more "personalized" approach to cancer staging. Cancer J Clin. 2017;67:93-9

8. Imamura T, Yamamoto $\mathrm{Y}$, Sugiura $\mathrm{T}$, et al. The prognostic relevance of the new 8th edition of the Union for International Cancer Control classification of TNM staging for ampulla of vater carcinoma. Ann Surg Oncol. 2019. https://doi.org/10.1245/ s10434-019-07238-6.

9. Kim SJ, An S, Kang HJ, et al. Validation of the eighth edition of the American Joint Committee on Cancer staging system for ampulla of Vater cancer. Surgery. 2018;163:1071-79.

10. Schueneman A, Goggins M, Ensor J, et al. Validation of histomolecular classification utilizing histological subtype, MUC1, and CDX2 for prognostication of resected ampullary adenocarcinoma. Br J Cancer. 2015;113:64-8.

Publisher's Note Springer Nature remains neutral with regard to jurisdictional claims in published maps and institutional affiliations. 